\title{
Similarities and Differences between Fansub Translation and Traditional Paper-based Translation
}

\author{
Fang Wang \\ School of Foreign Languages, Changchun University of Science and Technology, Changchun, China
}

\begin{abstract}
In the paper, fansub translation is compared with traditional paper-based translation. Their differences and similarities are summed up as well. Then there comes the most important part, in which fansub translation is connected to manipulation theory. The manipulation factors which influence the fansub translation and manipulation on fansub translation examples are also presented in this paper.
\end{abstract}

Index Terms - fansub translation, paper-based translation, equivalence

\section{INTRODUCTION}

A fansub (short for fan-subtitled) is a version of a foreign film or foreign television program which has been translated by fans and subtitled into a language other than that of the original.(http://en.wikipedia.org/wiki/Fansub) Fansub groups are groups of people who translate and add subtitle to the foreign film or foreign television program.

A fansub group is a team composed by the audiovisual lovers who also know a foreign language. They have the same interests and work together to translate the foreign movies, TV serials or videos, etc. into their own language and then share with each other, as well as publish on the internet for the netizens to download. The purpose for their activities is not to make money, but to enjoy the working process and the happiness it brings about. Besides, the fansub groups are also platforms for many language learners to practice their foreign language.

Currently, the foreign movies and TV series, as well as animations are quite popular in China. Among which the English movies and TV serials are especially popular, such as the Hollywood movies and the latest American TV serials Thus, it is the fansub groups which are quite well-known to the mass audience, whose members are basically ordinary netizens translate the American TV series and the Japanese animations. And in this thesis, we will focus on the fansubs who translate the American TV serials.

\section{Features of Feasub Translation}

The fansub groups mainly translate the latest foreign movies or TV serials into Chinese. The most obvious features of these translations are: almost synchronous with the original, without abbreviation or dubbing, and strictly based on the plot of the original play. Apart from these, the fansub translation also has some unique features.

Since most translators in the fansubs are not professional translators, their translation are not restricted by the orthodox translation standards. The professional translators always talk about what translation principles to follow, or what kind of methods to use. But the fansub members seldom think about that, they just translate any way they want as long as it is "suitable". All they care is to find the most suitable words or sentences for the original work. Generally speaking, their translations are more flexible and contain a lot of colloquial language and slangs. They are closer to our daily life. (Wang P., 2009)

Example: Original (Monologue): Oh, yeah. The chairs are rocks.

Chinese version: 是啊 椅子硬邦邦的

--Cited from Modern Family, fansubbed by YYeTs.

Observing the translation, we can find that the original word "rocks" is not translated directly into “石头”. On the contrary, the subtitler translated into the phrase “硬邦邦的”, which is always used in oral language. This translation not only transmits the original meaning of the sentence, but also expresses the feeling it brings, which is hard and cold. Also, the Chinese phrase is widely used in the daily life. The choice of this phrase makes the translation closer to the real life and more acceptable by the viewers.

The translators in the fansub groups are of different language levels, and their translation differs from each other. Some of their translations are very good, but some are not. There might exist many mistakes in some translation. Let alone the translation of many difficult materials which include many cultural, historical, or professional terms. Besides, the translation of the subtitle requires the translators to have good listening skills since many of them do have the original scripts. They listen to the original video, and then add the translated subtitle to the screen directly according to what they hear. 
One can never forget that the main function of media texts is entertainment and subtitles should serve their purpose without imposing too much of an extra effort on the viewer. The audiovisual audience stands in a completely different situation from that of the reader of a written text. Time constraints are highly determining for reading time is limited and, in most circumstances, the subtitle continuum does not allow to backtrack and reread a part that was not fully understood.

The translation of the fansubs is used to explain each scene of the video. So the length of the sentences is restricted to avoid causing problems of the audience since the human eyes can only view a certain words at a time. Thus, the translators have to make adjustments of the original language to make them short without changing the meaning.

As we can tell, the fansubs produce the translated subtitles for the convenience of the other audiences. So they always finish the translation in a short time because they know the audience is waiting. Sometimes, different fansubs will compete with each other and try to be the first to publish their translation. The first published version always has a larger market since many people are waiting. According to a data showed by Shooter.cn, during the popular season of Prison Break, YDY fansub group was the first to publish their translated subtitle on the internet. The publishing time was two past four p.m., and it was downloaded over 10,000 times. The other translated version by another fansub group was published three hours later, and the download rate was only $10 \%$ of the first one. (Shang Q. S., 2007) That's why all the fansubs want to be the first to publish the translated subtitles. As a result, it left the translators little time to think during translation.

Then in traditional paper-based translation, the medium is always papery. The translators do not have to possess good listening skills because it is not necessary while translating. Most of the time, all they have to do is to read the original material and then translate. Nor do they have to consider the length of each sentence to cater for the needs of the readers. The translators will use some translation methods and might follow some translation principles during their translation. And most of the time, the translators have plenty of time to translate. Thus, they can take their time to ruminate over their translation.

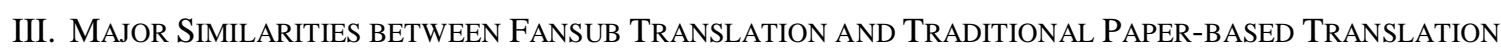

Although fansub translation and traditional paper-based translation has so many differences, they have some similarities at the same time. From the perspective of manipulation theory, it can be observed that both fansub translation and traditional paper-based translation are influenced by the popular ideology of the society in which it exists. Besides, the translators' ideology has a reflection on fansub translation as well as traditional paper-based translation. In most cases, the purpose of the translation is to attract other people to read, thus fansub translation and traditional paper-based translation all cater to the poetics of their target readers even though the degrees are different.

\section{A. Expression of the Translators' Ideology and Poetics}

The translators can never avoid putting their own ideology into their translation no matter whether they meant it or not. The words are the expression of the thoughts. The subtitles always express their thoughts in their translation, which are very obvious in the subtitles, for example:

Original (Monologue): I guess I just have to make lemonade out of the two of you.

Chinese version: 我想我只有尽力把你俩变成柠檬水了

生活给了你柠檬 (苦难) 你就把它变成柠檬水(幸福)

(If life gives you a lemon, make a lemonade)

--Cited from Big Bang Theory season 6, fansubbed by YYeTs.

The subtitler used annotation here to inform the viewers about the background knowledge. It means that the subtitler thought of the viewers understanding ability while subtitling.

The other example goes like this:

Original (Monologue): Look at that, the problem solved itself.

Chinese version: 你瞧 不攻自破了

--Cited from Big Bang Theory season 6, fansubbed by YYeTs.

The Chinese phrase "bu gong zi po" is an idiom, which contains higher traditional cultural atmosphere. There are also many examples of this type, which can express that they are inclined to use traditional Chinese idioms. As it has mentioned in the beginning of this thesis, most subtitlers are university students or have taken university education and have a great master of English and Chinese. Take TLF fansub group, which is founded in 2002 and focuses mainly on movies and American television serials as an example. It contains over 100 group members, and nearly all of them were born from the 60th to the 80th. Their education background includes middle school, university, master and doctor. As a result they are more inclined to use the civilized idioms (Jiang N., 2011).

As to traditional paper-based translation, this phenomenon is even more common. Every translator has its own preference, and every translation characteristic is the representation of the translator's ideology. Take Lin Shu as an example, he lived in the late Qing period most of his life time and acquired traditional Chinese culture from the very start of his childhood. He believed in and strongly advocated the superiority of traditional culture. He firmly believed that things with traditional culture, such as filial piety, had to be intactly remained. So his translation also contains many traditional words and traditional culture. Another example is Lu Xun, his translation are mainly literal because he held 
the view that literal translation is the best. Thus, his translation and translation method are the precise reflection of his ideology.

\section{B. Influence by the Poetics of the Society}

Lefevere is aware of the importance of manipulation in translation production and holds the opinion that translations are not made in vacuum. A rewriter or a translator does not translate in the vacuum: he or she is the product of a particular culture, of a particular moment in time, and the writing reflects those factors such as race, gender, age, class, and birth place, as well as the stylistic, idiosyncratic features of the individual. Manipulation is, as we have mentioned before, what the translator exercised on the translated text based on the various constraints he is subject to, such as the constraints imposed by power and ideology.

No matter whether it is subtitle translation or traditional paper-based translation, it can never avoid being influenced by the society. The current popular words, phrases, sentences in the society will have a reflection on the translation. Although the degree might be different, the influence exactly affects the translation. The manipulation school of translation theory holds the view that poetics decides the social status and influences the degree of translated articles.

\section{Catering to the Poetics of the Target Reader}

\section{According to Kaufmann:}

The function of a translation is dependent on the knowledge, expectations, values and norms of the target readers, who are again influenced by the situation they are in and by their culture. These functions determine whether the function of the source text or passages in the source text can be preserved or have to be modified or even changed.

What needs to be reinforced is the fact that subtitler's art is effective editing in order to make the most of turning the spoken word into written strings. The written strings should be rich enough to convey a multitude of meanings and yet simultaneously straightforward and clear, and also should go as unnoticed as possible.

Similarly, translators of the traditional paper-based translation also use some translation methods and techniques to make the target readers better understand and accept their translation. For example, Lin Shu used traditional Chinese while translating the foreign novels to attract more readers. The author herself also considered the poetics and acceptation ability of the target readers while translating the book Ultimate Guide to Wildness Living.

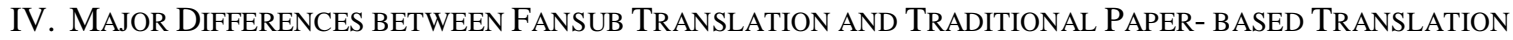

The fansub translation is quite different from the traditional paper-based translation in several aspects: the history, the translator, the translation object, the translation purpose, the main audience, the influencing factors and translation features, etc.

\section{A. The History}

The fansub translation is newly born compared with traditional paper-based translation. As it is recorded, fansubs originated in the explosion of anime during the 1980s in Japan. (http://en.wikipedia.org/wiki/Fansub) In China, the history of the fansub groups can be traced back to about 10 years ago. In 2001, with the wide spread of the internet, the netizens all over the world began to publish the video programs made by themselves.

Yet the traditional paper-based translation can be traced back to the ancient times when the Chinese people translated the Buddhist Scriptures. It has gone through a long history till now, which makes it more developed than the fansub translation.

\section{B. The Translator}

The translation subject of the fansub translation is no doubt members in the fansub groups, many of whom are not professional translators. The ex-group leader of YDY fansub group is a clinical psychologist, and one of the founders of the Ragbear fansub group is a policeman. (http://www.guancha.cn/Celebrity/2012_09_25_99792.shtml) Students take a great part, among which most are Chinese students studying abroad. Few of them know or have done translation before, and some of them are even not majoring in foreign language. They are mainly young people who have strong interests in the European and American culture. In an interview of Xiao Fu, one of the founders of the most influential fansub groups FRM, he said: "in the subtitle translation circle, the true identities of the translators are always a secret. They might be a Chinese student studying abroad, or an office worker, or even a housewife in Downing Street. The only thing connects them is the internet, as well as their love of the foreign TV serial. But, they do have some common features. Generally, all of them have a lot of time to sit in front of the computer. Among these members, students, homeboys and homegirls take a great part. Their general age is between 20 and 25. And of course, they have strong foreign language abilities." (http://news.qq.com/a/20090803/001004.htm)

However, traditional paper-based translation is always done by professional translators, or at least professional language learners. Their knowledge and master of the source language is much better than the fansub translators. Besides, translators of the traditional literature enjoy great honor. As we can see from the translation history in China, there are countless famous translators. They have good reputations and are well respected by the whole society. However, fansub translators are always unknown to the public. They stay low, and only appear as an ID number. They do the translation secretly and keep quiet most of the time. 


\section{Translation Objects and Purpose}

The translation objects of the fansubs are audiovisual products, such as movies, TV serial, etc. The translation objects of traditional paper-based translation are mainly articles, papers, manuals and books, etc.

The translation purpose of the fansubs is to share, to learn and to improve. They always stick to the principle of sharing for free, and maintain to be the organization of non-commercial. They translate because they like the source video products and want to share with the others. They watch the American TV serial to learn English language and culture. And then they translate to practice English and to provide convenience for the other audience. Also, some people do the translation and publish it in the forum because they want to win the scores of the forum. The more scores they have, the more videos and TV programs they can download from the forum. The member of the CPPCC Chen Weiya said: "I think what supports the fansubs translation is the interest, as well as the satisfaction of being watched by the netizens. They do this for the interests and faith, but not for money. This is very admirable." (http://news.qq.com/a/20100313/000218_1.htm )

As to the translation purpose of the traditional paper-based translation, we cannot conclude it in several sentences. All we can tell is that they are not just for enjoyment. For example, the translation purpose of the Buddhist sutras is to influence the thoughts of the people, and elevate their humanity. The translation of the western scientific and technical literature in the late Qing Dynasty was popular and was attached importance by many scholars because of the social situation at that time. (Chen F. K., 2009) They want to introduce the advanced science and technology to improve China's under-developed situation. Translation purpose of the world famous literature works is for the admiration and enjoyment of the people.

\section{The Target Receiver}

The main audiences of the fansubs are people of the age from 19 to 40 . According to a research made by the YDY Forum, among all the 1000 netizens who have participated in the research, $75 \%$ are in the age group between 19 and 40 , and $71 \%-85 \%$ has a junior college education degree. (http://ent.sina.com.cn/v/u/2009-04-08/13082461399.shtml) Of course this data may not be so accurate, but it does represent a phenomenon. The target readers of traditional paperbased translation are the mass people, and it differs depending on the exact translation. The audience of the professional materials in a certain area may be the experts in that area, such as medical translation, software translation. And the audiences of the well-known literature works are the public.

\section{E. The Influencing Factors}

The translation of the fansubs is influenced by several factors, such as the appetite of the audience, the personal preference of the translator, the present popular terms on the internet, etc. Taking from the view of the manipulation theory, the translation of the fansubs is manipulated by the ideology of the mass audient, the ideology of the translators and the social ideology, as well as the poetics of the translators. But the influence of the patronage can nearly be neglected, since the translation activity is spontaneous by the audiovisual fans. Apart from that, the influence of censorship on the fansub translation is not very strong due to its special features. Since the fansubs always keep a low profile, and the subtitled videos are not for commercial use, the censorship to it is not extremely strict. The fansub translation is a minority activity, so its censorship has not become a complete system yet.

As to the traditional paper-based translation, it is not only influenced by theideology of the translator, the readers and the society, but also by the patronage. As we can see, most of the traditional paper-based translations are sponsored by a third party, which is what we called patronage, so they are inevitably influenced by it. For example, the translation of the Buddhist sutras in the Tang Dynasty is influenced by the government; and the translation of many books in the current society is influenced by the publisher. The translator's poetics also influences the translation process, but it is not as evident as in the fansub translation. The censorship to the traditional paper-based translation is developed and mature, and all the translation works are under strict examination.

\section{AdVANTAges of FAnsub Translation}

Although fansub translation is non-mainstream compared with traditional paper translation, it still has advantages. It connects closely with the social development, enlarges the translation scope and promotes the development of translation. Besides, it also improves reading skills, boosts foreign language skills and facilitates easy and cheap international program exchange.

\section{A. Promoting the Development of Translation and Translation Study}

It is developing fast and connects closely with the current society, which makes it more popular than the translated books. This can be traced back to the origin of the fansub group members, most of whom are netizens. They are familiar with the popular words on the internet, such as “狗血”, “你妹啊”, “海翻了”, etc. Most of these words appear in the fansub translation and thus attract the resonation of many viewers. It can be claimed as a form of translation which comes from the people and shared by the people. Whether this kind of translation would last long in the translation system or not, it has inevitably promoted the development of translation. 
Besides, it enlarges the scope of translation. Traditionally, when speaking of translation, it means on-the-paper translation. However, the emergence and development of fansub translation makes the translation world more and more colorful. Translation has broken through the boundary of paper and texts and accessed to the audiovisual area.

Last but not least, it will boost translation studies. Subtitle translation is different from traditional paper-based translation. It has its specific features, such as using a lot of simplification, annotation, web language, and sometimes the subtitlers have to do audio translation. All these features are good research points of translation studies.

\section{B. Improving Reading Skills and Foreign Language Skills}

In a culture which favors audiovisual media, subtitles in foreign productions constitute an important and effective reading drill for both adults, including immigrants, and for children. Interlingual subtitles tend to be read even by viewers who understand the original language spoken. Similarly, intralingual subtitles usually trigger reading behavior in a perfectly hearing audience. This may of course sometimes be due to the 'natural acting' favored in many contemporary film and TV productions, which renders parts of the dialogue semi-inaudible to most people. But the prime reason for this 'doubled reception' of spoken lines on TV is that most literate people simply cannot avoid reading text on screen. In Denmark, subtitles are now the primary reason that children want to learn how to read, and normallyhearing people who never read the Danish non-optional subtitles are nowadays considered dyslectic.

According to Belgian studies, reading domestic-language subtitles while watching a foreign-language production improves foreign-language vocabulary skills, in particular in children. And in Italy, a promising, interactive and concordance-based method for learning minority languages through subtitled film sequences is presently being developed.

\section{Facilitating Easy and Cheap International Exchange}

As is mentioned before, fansub groups are volunteer translation groups. The subtitlers in the fansub groups do the translation without charging any fees. This action improved the spread and acceptability of foreign audiovisual products in China. Since audiovisual products, especially television serials, contain a lot of cultural knowledge, such as life style, eating habits, communication features, etc., the viewers will learn those features while watching audiovisual products. Meanwhile, international exchange has also been increased at the same time.

\section{Disadvantages of Fansub TRANSLATiON}

Although fansub translation contains many popular words and expresses the current popular trends on the website and throughout the whole society. It cannot be assured that fansub translation is the best without any problems. Since every coin has two sides, so is fansub translation. Meanwhile, the using of popular words in fansub translation also has its shortcomings.

\section{A. Instantaneous of Web Language}

It is known to all that nothing could stay popular forever. When it comes to web language, it is more obvious. Many words became popular on the internet instantaneously, and the subtitlers always use those popular words in the subtitle translation. We cannot tell whether those popular words will stay popular for a long time. Besides, it is always the case that those popular words will vanish quickly. Thus, it is probably that the subtitle translation will be out of date some day.

Right now, there are many disputes about the fansub translation. Some people are in favor of it and highly praise the translation, while some people dislike it. It is true that comparing with the traditional literary translation, fansub translation is not that classic and sometimes temporary. And the language used in the translation is not long-lived.

\section{B. Negative Influence on the Audiences}

Although adding subtitles to the English programs can help the audience to learn English, it may also cause some negative influence on the audience if the translated subtitles are incorrect. As the author has noticed during watching English TV serials and movies, there are always some translation mistakes. The audiences would be misled if they learn English based on the wrong translations.

Take the phrase “give my best to him” for example. The correct Chinese translation is “带我向他问好”, but some fansub group translated it into “把我最好的给他”. The other phrase “she's such a pain in the ass” should be translated into “她真讨厌”, but the fansub group translated it into “她的殿部有疼痛感”. If the audience is not good at English and trusted the subtitle, they will be misled.

\section{Problems CONFronting FAnsub Groups}

Many problems existing in the fansub translation are unique, since they seldom appear in traditional paper-based translation.

\section{A. Legal and Ethical Issues}


With its popularity and development, fansub groups have attracted more and more attention. They have received the support of the mass viewers, but also are facing with criticism and misunderstanding. From the perspective of maintaining the copyright, fanusb groups may be criticized of piracy. Although they always add those words "this is only for study and communication, please do not use it for commercial purpose" in front of their subtitled programs, the subtitled programs are used by some illegal peddlers to make pirated discs.

On April 1st, 2009, the State Administration of Radio Film and Television prescribed clearly in the notice about strengthening the management on internet audiovisual program content that "any movies, television programs, cartoon programs and theoretical document audiovisual products should not broadcast on the internet unless certified". Thus many websites which provide broadcasting and downloading of the subtitled foreign programs were shut down, such as tudou.com, youku.com and BT forum. As the translator of the subtitles, fansub groups were criticized of causing those piracies and blamed by many people.

However, if the fansub groups only translate the subtitles and do not add them to the programs, they would be able to avoid the criticism. It is a fact that many Chinese audiences do not know how to add subtitle to the program. But since every fansub group want to attract more fans, their help and thoughtful of providing subtitled programs lead to their infringement of law.

Fansub groups are global phenomenon and Chinese fansub groups are only a small part. Although the Chinese fansub groups might face some problems during their development, the fansub groups in America and Europe have avoided some of the problems by only providing translated subtitles. They would not add those subtitles to the programs, which could avoid being accused of illegal. May be Chinese fansub groups could also use this way to prevent from illegal or piracy (Liu X. J., 2011).

\section{B. Quality Problems}

It should be admitted that the situation of the subtitle translation is quite a chaos right now. There are no uniform standards to regulate the fansub translation. Moreover, there exist certain people whose translate purpose is only to gain scores of the forum. So they are not serious with their translation and would make many mistakes. There are also some fansubs who only care about the amount of their translation without considering of the quality. They do not have a censor to guarantee the translation quality. So when watching the videos with subtitles, we can easily find a lot of mistakes. Generally speaking, the mistakes can be concluded in the following types:

1. Format errors

Take the most common "srt" format as an example, which can be open by the

notepad of the computer system. Its format is like this:

180

00:14:53,962 -; 00:14:56,362

我能跟你的朋友谈一会儿吗?

181

00:14:56,598 -; 00:14:58,828

你是他的律师吗?

There are three kinds of format errors:

a. While translating, the timing code is deleted. Only the number and sentences are left. For example:

180

我能跟你的朋友谈一会儿吗?

This kind of subtitle cannot be loaded into the videos, and there will appear error display like XXX faults.

b. The English subtitle is not removed clean. For example:

180

00:14:53,962 -; 00:14:56,362

那是他的拿手好戏.

c. The blank line is missed between two sentences. If so, the number, timing

code and contents of the next sentence will all be displayed on the screen.

2. Punctuation errors

Although the punctuation seems unnecessary, it actually influences the quality of the subtitle, and sometimes even the understanding of the plot. As to whether add punctuation or not, the group members of HST once had a discussion. And their discussion result goes like this: unified use Chinese punctuation, or do not use punctuation except “?”, “《》” which will influence the understanding of the meaning. However, not all fansub groups have punctuation standard. Thus this kind of error is difficult to avoid.

3. Disunity translation of names

According to the customs of HTS fansub group, the names of people and places should also be translated. The abbreviations such as WTO, CIA, FBI, etc. are well known to the people, so they can be directly used in the translated subtitle. While translating the others names, the translators should follow the general customs. For example: the American president Kennedy should be translated into “肯尼迪”, because it has become a custom and the name is well known to the Chinese people. But if it is translated into “克妮蒂”, the audience will not be able to understand who it 
really is. Sometimes, the names will be translated into the wrong sex. Such as the name Kyle can be translated into “凯 尔” or “凯利”. However, if it belongs to a man but is translated into “凯莉”, the audience will get confused.

Besides, when one TV serial is translated by several people, this disunity will also appear. Sometimes the name of the same character will change in different episodes. Take Sex and City as an example, the name of the main character Mr. Big was translated into “大人物” in the first several episodes, but in the later ones it was translated into “比格先 生”, “彼格先生”, and so does the names of several other figures. Thus, this will cause the audiences’ inadaptability.

4. The sentences too long

This is the thing that many new subtitle translators will neglect. The size of the screen requires there should be no more than 20 Chinese characters in one line, and no more than 3 lines all together on the screen.

5. The translated sentences difficult to understand

Each sentence of the subtitle will only appear several seconds on the screen, thus the translators should use the simplest sentence to express the most necessary information. Translate the sentences into "tongue twisters" should be strictly avoided. A sentence can have many kinds of translation based on the specific condition. So the translators can choose the easiest understandable sentences as long as it keeps the original meaning. For example,

"But he's afraid if she finds out he's gonna pay all that dough, she won't let him."

“但他担心是否她已经发现他能支付所有的钱, 她不会的。”

There are three "he" and two "she" in the English sentence, which will make our Chinese people confused. But the Chinese translation is even worse because we totally cannot understand the meaning. So the translator should divide the meaning and then separate the sentence accordingly. It can be translated as:

“他准备支付所有的钱，但担心她发现后不允许这么做。”

6. Understanding errors

Some English words have several meanings, and may be the meaning the translator knows is not the suitable one in the sentence. So if the translator only translates according to their existing knowledge, they will make mistakes. Such as: "Why, it's nearly nine o'clock."

When there is a question mark behind the word "Why", we usually translate into “为什么”. But in this sentence, there is a comma following behind, so it cannot be translated into “为什么”. At this time, the translator should consult dictionaries and translation software to figure out the suitable meaning. Therefore, we can translate the sentence into:

“啊, 快要九点了。”

Another example goes like this:

"And right away you turned yellow.

Yellow?"

The next sentence is: "Yellow is a color you figure on in a murder."

The direct translation of the sentence goes like this:

“紧接着你就变黄了。

黄了?"

But the audience will certainly not understand the meaning.

So, based on the meaning, the sentence could be translated like this:

“你立刻吓得脸都黄了。

黄了?"

7. Blind translations

In the fansub HTS, if the proofreader do not watch the video but directly proof the English and Chinese subtitle, it is called "blind proofread". And accordingly, direct translation without watching the video will be called "blind translation". Since the biggest difference between subtitle translation and traditional article translation is that the subtitle is closely connected with the plots. For example, the word "you" always appear in the program. Such as:

"Why don't you"

Whether it should be translated into “你为什么不” or “你们为什么不”? It will depend on the actual situation of the plots. If it is translated without connecting with the plots, many mistakes will appear.

8. Multiple translations

Multiple translation is not an error in itself. But if all the translators do not watch the program thoroughly, mistakes might appear. The translation of some terms, the language style and the expression methods might be different when translated

by different people. Thus, different kinds of mistakes will emerge.

9. Too rigid or too flexible

According to the traditional paper-based translation theory by Yanfu, "faithfulness, expressiveness and elegance" are the standards to judge a good translation. The translators can get the meaning of the English sentence, but whether they can translate them into good Chinese is a question. The translation of some words, especially some verbs like "take, get" are more difficult since they have many meanings. For example: "I'll get the car" should be translated into “我去 开车, 我去把车开过来”, but not “我去拿车”. “To saddle a horse” means “给马装上马鞍” but not “去鞍上马” which 
is totally English style Chinese. Too rigid is not good, and so is too flexible. In the serious conditions, if the word "girl" is translated into "MM", or “美眉”, then it is not good.

10. Too many wrong words and sentences

Since the translators in the fansubs are always in a hurry and translate in a short time, the appearing of wrong words and sentences is a normal occasion. Sometimes there even exist some silly mistakes, which should be firmly eradicated. (http://www.douban.com/group/topic/1040982/)

\section{REFERENCES}

[1] Chen F. K. (2009). A history of translation theory in China. Shanghai: Shanghai Foreign Language Education Press.

[2] Jiang N. (2011). Fans cultural network group reading subtitles. Journal of Ningbo Radio \& TV University, 9, 1-2.

[3] Liu X. J. (2011). Poaching game - domestic cultural research group subtitle. Shanxi: Xibei University.

[4] Wang P. (2009). "Hidden epidemic" Where is the way? - "Subtitle group" translated aspects. Movie Review, 17, 63-64.

[5] Shang Q. S. (2007). "Prison Break", the Chinese secret epidemic. Yilin, 3, 44-45.

Fang Wang, MA in linguistics, earned in Jilin University, Jilin Province, China, in 2007. The major field is critical discourse analysis.

She is now the lecturer in CUST and is studying for her Ph.D. degree in Jilin University. His main published articles include Resolving Ambiguity in Familiar and Unfamiliar Casual Speech, Exploring Teaching Beliefs in Teaching EAP at Low Proficiency Levels. 